\title{
Variable Dopamine Release Probability and Short-Term Plasticity between Functional Domains of the Primate Striatum
}

\author{
Stephanie J. Cragg \\ Department of Pharmacology, University of Oxford, Oxford OX1 3QT, United Kingdom
}

Release of the neuromodulator dopamine (DA) is critical to the control of locomotion, motivation, and reward. However, the probability of DA release is not well understood. Current understanding of neurotransmitter release probability in the CNS is limited to the conventional synaptic amino acid transmitters (e.g., glutamate and GABA). These fast neurotransmitters are released with a repertoire of probabilities according to synapse type, and these probabilities show activity-dependent plasticity according to synapse use. Synapses for neuromodulators such as DA, however, are designed for signaling that diverges temporally and spatially from that for fast neurotransmitters: DA receptors are exclusively metabotropic and at sites that extend to extrasynaptic locations and neighboring synapses.

In this study, the release probability of DA was explored in real time in limbic- versus motor-associated functional domains of the striatum of a primate (marmoset; Callithrix jacchus) using fast-scan voltammetry at a carbon-fiber microelectrode. We show that the probability of axonal DA release varies with striatal domain. Furthermore, release probability exhibits a short-term, activity-dependent plasticity that ranges from depression to facilitation in motor- through limbic-associated regions, respectively. Rapid plasticity does not result from metabotropic $\mathrm{D}_{2}$-like $\mathrm{DA}$ receptor activation or ionotropic $\mathrm{GABA}_{\mathrm{A}}$ receptor effects but is dependent on $\mathrm{Ca}^{2+}$ availability.

These data reveal that rapid dynamics in DA release probability will participate in the transmission of the patterns and frequencies encoded by DA neuron action potential discharge. Furthermore, the regional variation in these features indicates that limbic- versus motor-associated DA neurons are permitted to generate diverse DA signals in response to a given firing pattern.

Key words: release probability; synaptic plasticity; short-term facilitation; short-term depression; basal ganglia; volume transmission; presynaptic; extrasynaptic; nucleus accumbens core; nucleus accumbens shell; putamen; caudate; sensorimotor; limbic system; marmoset; monkey; phasic; tonic

\section{Introduction}

The strength of glutamate and GABA synapses in the CNS is highly dynamic. In particular, the release probability of these neurotransmitters can vary dynamically with synapse use and encode a neuronal history or short-term memory (Zucker, 1989). One result is frequency filtering (Thomson, 2000) in a synapsespecific manner (Stevens and Wang, 1995; Dobrunz and Stevens, 1997). Such activity-dependent plasticity can fine-tune release to an operating range appropriate to the pattern and frequencies of activity of each type of synapse. For these conventional synaptic neurotransmitters, rapid and local regulation of availability is appropriate to their action: fast ionotropic responses at intrasynaptic receptors.

Signaling by the neuromodulatory amines [e.g., dopamine (DA)], however, diverges in design. DA receptors are exclusively metabotropic and located abundantly at extrasynaptic sites (Yung et al., 1995). Thus, signaling by DA will diverge temporally and spatially from that by GABA and glutamate. Moreover,

\footnotetext{
Received Jan. 8, 2003; revised Feb. 20, 2003; accepted March 4, 2003.

This work was supported by a Beit Memorial Trust Fellowship for Medical Research and an E. P. Abraham Research Fellowship (Keble College). I thank Drs. M. Bevan, C. Hille, S. Judge, C. Price, and M. Rice for their helpful contributions.

Correspondence should be addressed to Dr. Stephanie J. Cragg, University Department of Pharmacology, 0xford 0X1 30T, UK. E-mail: stephanie.cragg@pharm.ox.ac.uk.

Copyright $\odot 2003$ Society for Neuroscience $\quad$ 0270-6474/03/234378-08\$15.00/0
}

whereas synaptic overflow and cross-talk is restricted for glutamate and GABA (Rusakov et al., 1999), DA appears to be designed for signaling beyond a point-to-point synapse (Garris et al., 1994; Descarries et al., 1996; Rice, 2000), a process known as volume transmission (Fuxe and Agnati, 1991). Whether synaptic plasticity is a feature of release common to these disparate forms of neurotransmission has not been determined previously.

Short-term plasticity of DA release will be pivotal to DA function. Mesostriatal DA neurons fire at low, irregular frequencies $(0.5-8 \mathrm{~Hz})$ or at faster frequencies in short apparent bursts [ two to four pulses at interspike rates of $\sim 20 \mathrm{~Hz}$ (rodents) (Grace and Bunney, 1984a,b) and higher (Hyland et al., 2002), and up to $\sim 100 \mathrm{~Hz}$ (task-related in primates) (Schultz, 1986)]. Dynamic plasticity in the probability of DA release will govern, for example, the transmission of single versus multiple (e.g., burst-spike) firing by each DA neuron.

Two major mesostriatal DA neuron populations innervate the striatum, namely the mesolimbic (A10; ventral tegmental area) and nigrostriatal (A9; substantia nigra pars compacta). These two pathways are differentially involved with the diverse roles of DA: limbic, associative, and sensorimotor. Furthermore, these two populations are differentially the sites of the effects of cocaine (Carboni et al., 1989) and the primary dysfunction in Parkinson's disease, respectively (Kish et al., 1988; Gibb and Lees, 1991). Known physiological differences between these DA neurons include differences in $\mathrm{Ca}^{2+}$-binding proteins (Haber et al., 1995), 
a

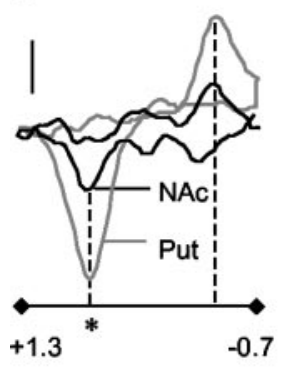

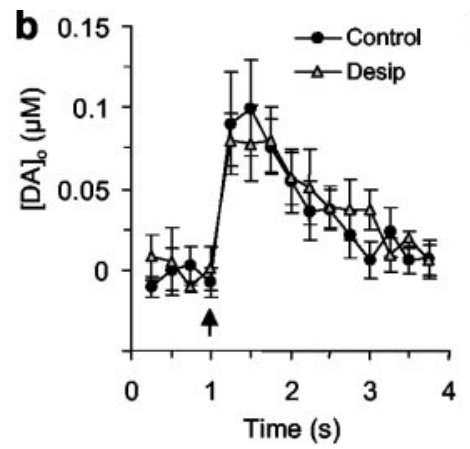

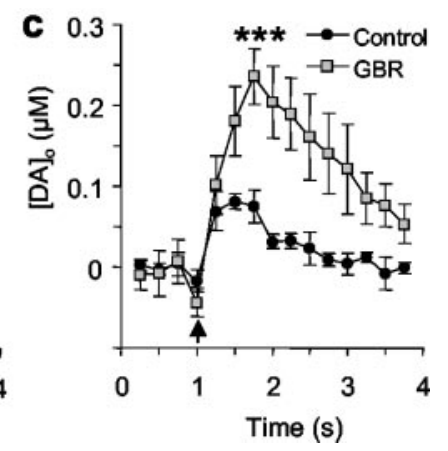

Figure 1. Cyclic voltammograms and uptake transport identify DA. a, Cyclic voltammograms obtained in putamen (Put; dorsolateral; gray) and, at $6 \times$ amplification, NAc (lateral; black). Scan range, -0.7 to +1.3 to $-0.7 \mathrm{~V}$. Dashed lines indicate oxidation (asterisk) and reduction peaks for DA. Calibrations: putamen, $6 \mathrm{nA} ; \mathrm{NAc}, 1 \mathrm{nA} . b, c$, Mean $[\mathrm{DA}]_{0} \pm \mathrm{SEM}$ versus time caused by a single pulse (arrow) in NAc (ventromedial) in control (circles) and during inhibition of either the NET [desipramine (Desip; 300 nм); triangles] (b) or DAT [GBR 12909 (GBR; 500 nм); squares] (c). b, Desipramine had no effect on removal rate or $[D A]_{0}(n=6) . c$, GBR 12909 inhibited removal and enhanced $[D A]_{0}\left({ }^{* *} p<0.001 ; n=5\right)$.

membrane currents (Wolfart et al., 2001), and the regulation of DA behavior (e.g., uptake kinetics) (Jones et al., 1995; Cragg et al., 2000, 2002). It is notable that DA availability for release has been linked to $\alpha$-synuclein content in the mouse (Abeliovich et al., 2000). It is vital to our understanding of the repertoire of function and pathology that we understand any differential operation of DA neurotransmission by these neurons.

In this study, we have explored the probability of DA release in the primate striatum by observing DA release in real time using fast-scan cyclic voltammetry at a carbon-fiber microelectrode. By detecting the extracellular concentration of DA ([DA $\left.]_{\mathrm{o}}\right)$, this method monitors presynaptic release directly. We explored DA release in two major functional territories to reveal the repertoire of dynamic DA release probabilities (i.e., short-term plasticity).

\section{Materials and Methods}

Brain slice preparation. We have demonstrated previously that the repertoire of DA behavior in the primate is only partly appreciated by study of the rodent brain (Cragg et al., 2000). Thus, this study was performed in the striatum of a primate, the marmoset (Callithrix jacchus). Male marmosets (1-2 years of age) from an established colony were killed by intraperitoneal overdose of pentobarbitone. Striatal slices $(400 \mu \mathrm{m})$ were prepared in ice-cold, HEPES-buffered physiological saline saturated with $95 \% \mathrm{O}_{2}-5 \% \mathrm{CO}_{2}$, as described previously (Cragg et al., 2000, 2002). Striatal coordinates were as follows: midcommissural to rostral, anterior to anteroposterior zero plane by $8.5-11.5 \mathrm{~mm}$ (Stephan et al., 1980).

Voltammetry and microelectrodes. All recordings were made at $32^{\circ} \mathrm{C}$, as described previously (Cragg et al., 2000, 2002), in bicarbonate-buffered artificial CSF (aCSF) $\left(95 \% \mathrm{O}_{2}-5 \% \mathrm{CO}_{2}\right)$ containing $2.4 \mathrm{mM} \mathrm{Ca}^{2+}$ (except where indicated otherwise). Evoked $[\mathrm{DA}]_{\mathrm{o}}$ was measured using fastscan cyclic voltammetry with $6 \mu \mathrm{m}$ carbon-fiber microelectrodes beveled to a point (exposed length, $\sim 30 \mu \mathrm{m}$; MPB Electrodes, London, UK) and a Millar voltammeter (PD Systems, West Moseley, UK) (Cragg et al., $2000,2002)$. Scan rate was $800 \mathrm{~V} / \mathrm{sec}$, from -0.7 to 1.3 to $-0.7 \mathrm{~V}$ versus $\mathrm{Ag} / \mathrm{AgCl}$; sampling frequency was $4-8 \mathrm{~Hz}$. Data are plotted at $4 \mathrm{~Hz}$ for clarity. Cyclic voltammograms have the background current subtracted. Electrodes were calibrated in aCSF. The detection limit for $[D A]_{0}(\sim 2 \times$ noise) was $\sim 20 \mathrm{~nm}$.

Electrical stimulation. To evoke DA release, stimulus pulses (100 $\mu \mathrm{sec}$ in width) were applied with surface bipolar electrodes (Cragg and Greenfield, 1997; Cragg et al., 2000, 2002). Multiple release sites are recorded (Stamford et al., 1986). The sources of variability in release other than those attributable to the type of neuron were reduced by using stimulation currents $(0.3-0.8 \mathrm{~mA})$ that generated $95-99 \%$ of maximum, singlepulse release. Thus, the stimulus evokes release from a near-maximal number of release sites in the vicinity of the stimulating electrode in a

synchronous manner and according to the inherent probability of release $\left(\right.$ prob $\left._{\mathrm{R}}\right)$. The stimulus recruits action potentials, because release is TTX sensitive (data not shown). Thus, the paradigm represents on a population level the response to successful invasion of release sites by these action potentials. In paired-pulse experiments, single- and paired-pulse protocols were alternated at $60 \mathrm{sec}$ intervals; at these intervals, single-pulse release is recovered fully.

Data analysis. Release caused by the second in a pair of pulses $\left(P_{2}\right)$ is determined directly by subtracting the single-pulse $\left(P_{1}\right)$ from the summated paired-pulse $\left(P_{1}+P_{2}\right)$ response. A complex dependence of uptake on the peak concentration did not need to be incorporated or modeled (Cragg et al., 2000, 2002) because of the independence of the paired-pulse ratios from uptake (see Results). Data are means \pm SEM, and sample size $(n)$ represents the number of recording sites. Limited data from putamen in Figures 1 and 2 have been published in part previously (Cragg et al., 2000); these data are included where necessary for comparison with nucleus accumbens (NAc). The number of animals in each experiment was 2-10. Comparisons for differences in the means were assessed by one- or two-way ANOVAs and post hoc multiplecomparison $t$ tests (Newman-Keuls).

\section{Results \\ Variation in single-pulse release from ventral through dorsal striatum}

The primate striatum is delineated into different functional domains. In particular, corticostriatal connectivity defines three distinct but interrelated functional domains that span the ventral to dorsal striatum: ventromedial (vm)/limbic-, central (mid)/ associative-, and dorsolateral (dl)/motor-associated domains (Kunzle, 1975; Selemon and Goldman-Rakic, 1985; Lynd-Balta and Haber, 1994b; Haber and McFarland, 1999). Each functional domain receives a different degree of innervation from the two major mesostriatal DA neuron types (A9/nigrostriatal; A10/mesolimbic) (Szabo, 1980; Parent et al., 1983; Lynd-Balta and Haber, 1994a; Haber et al., 2000). The net result across the three nuclei that comprise the striatum (putamen, caudate, and accumbens) is an overlapping continuum of mesostriatal projections that ultimately segregate along a ventromedial-dorsolateral axis as predominantly A10 in the ventromedial striatum and A9 in the dorsolateral striatum.

A single-stimulus pulse $(100 \mu \mathrm{sec})$ could evoke the rapid release and removal of the electroactive substance DA. A perimaximal stimulus current was used (see Materials and Methods). Cyclic voltammograms throughout the dorsal and ventral striatum were characteristic of exogenous DA (Fig. 1a) (peak potentials: oxidation, $500 \mathrm{mV}$; reduction, $-200 \mathrm{mV}$ vs Ag/ $\mathrm{AgCl}$ ) and endogenous DA recorded previously in primate putamen and caudate nuclei (Cragg et al., 2000, 2002). Uptake transport was identified as being via the DA transporter (DAT) in NAc, as shown previously in the dorsal striatum. Single pulse-evoked signals and extracellular lifetime were unaltered by competitive inhibition of the norepinephrine transporter (NET) in NAc (Fig. 1b) [desipramine (300 nM); $n=6$; three applications] or dorsal striatum (Cragg et al., $2000,2002)$ but were elevated by competitive inhibition of the DAT in NAc (Fig. 1c) [1-(2-[bis-(4-fluorophenyl)methoxy] ethyl)4-(3-phenylpropyl)piperazine (GBR 12909; $500 \mathrm{~nm}$ ); one-way 

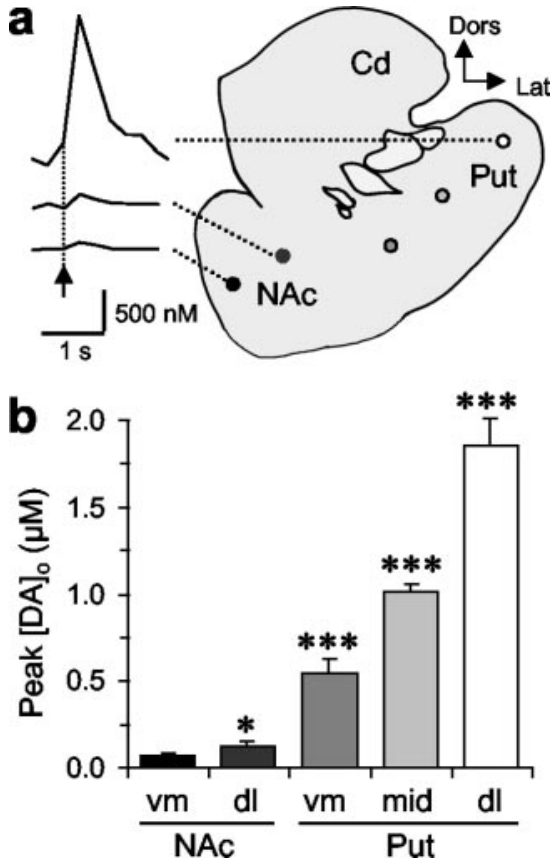

Figure 2. Availability of DA for release from ventral through dorsal striatum. $a$, Typical observations of $[D A]_{0}$ versus time after one stimulus pulse (arrow) in NAc versus dorsolateral putamen (Put) in coronal sections of marmoset striatum. Cd, Caudate; Dors, dorsal; Lat; lateral. Calibration for $[\mathrm{DA}]_{0}: 500 \mathrm{~nm}, 1 \mathrm{sec}$. Filled circles are site-specific and indicate sites of recording for mean data, corresponding to the filled bar in $b . b$, Mean peak $[D A]_{0} \pm$ SEM evoked at five loci indicated in $a$, along a ventromedial-dorsolateral axis. DA release varies between and within each region of the ventral and dorsal striatum (two-way ANOVA; $p<0.001$ ). Post hoc comparisons with ventromedial NAc are illustrated $\left({ }^{*} p<0.05 ;{ }^{* * *} p<0.001 ; n=7-27\right)$.

ANOVA; $p<0.001 ; n=5]$, as shown previously in the dorsal striatum (Cragg et al., 2000, 2002).

Peak $[\mathrm{DA}]_{\mathrm{o}}$ evoked by a single-stimulus pulse were recorded and compared with tissue DA content. Peak evoked $[\mathrm{DA}]_{\mathrm{o}}$ varied significantly within and between striatal nuclei along the ventromedial-dorsolateral axis (Fig. 2) (two-way ANOVA; $p<0.001$; $n=7-27)$. Within each nuclei, evoked $[\mathrm{DA}]_{\mathrm{o}}$ was significantly greater at dl than at vm loci by approximately twofold within the NAc $(p<0.05)$ and by more than threefold within the putamen, as reported previously (Cragg et al., 2000). Furthermore, an overall trend was apparent across the ventromedial-dorsolateral extent of striatum: a continuous gradient in single pulse-evoked release presented a marked 20 -fold lower $[\mathrm{DA}]_{\mathrm{o}}$ in NAc (vm) than in putamen $(\mathrm{dl})$ (Fig. $2 b)(p<0.001)$. However, this regional heterogeneity in evoked $[\mathrm{DA}]_{\mathrm{o}}$ exceeds that of tissue content of DA (Cragg et al., 2000) by an order of magnitude. This discrepancy between the variabilities of packing density compared with release thus reveals a large diversity in the probability of release between functional territories and, consequently, DA neuron types, whereby DA release probability is significantly lower in limbic- than in motor-associated regions.

\section{Paired-pulse plasticity correlates with striatal domain}

To explore further the variable probability of release between DA neuron types and the dynamic properties of release that will occur during rapid-burst firing, stimulus pulses were paired at a short interpulse interval $\left(t_{\mathrm{IPI}}\right)$ of $10 \mathrm{msec}$, which can occur during burst discharge of DA neurons in awake monkeys (Schultz, 1986) and awake rats (Hyland et al., 2002). Typically, at amino acid synapses (e.g., glutamate, GABA), the initial release probability is inversely correlated with the release evoked by the subsequent, paired stimulus $\left(t_{\mathrm{IPI}}<100 \mathrm{msec}\right)$. Here, the fraction of $P_{1}$ that was released by $P_{2}$ [i.e., the paired-pulse ratio $\left(P_{2} / P_{1}\right)$ ] varied markedly $(p<0.001)$ in a manner that was correlated with territory, ranging from a paired-pulse depression $(\mathrm{PPD})$ in the dorsolateral putamen (Fig. $3 a, c)\left(P_{2} / P_{1}=0.18 \pm 0.12 ; P_{2}\right.$ vs $P_{1}, p<$ $0.001 ; n=11-15)$ to a paired-pulse facilitation (PPF) in the ventromedial NAc (Fig. $3 b, c)\left(P_{2} / P_{1}=1.97 \pm 0.15 ; P_{2}\right.$ vs $P_{1}, p<$ $0.001 ; n=20-23)$. Paired-pulse ratios were inversely related to $P_{1}$ across striatal territories (Fig. $3 c$ ) and also to $P_{1}$ normalized for the regional variation (approximately threefold) in tissue DA content (Cragg et al., 2000) (Fig. 3c, dashed line) $\left(R^{2}=0.97\right)$. Whereas the paired release in ventral striatum (NAc) showed $\mathrm{PPF}$, or at the minimum at least parity, within the dorsal striatum (putamen), only PPD was observed. These observations indicate a greater (initial) DA prob ${ }_{\mathrm{R}}$ at increasing dorsolateral coordinate.

Plasticity in DA release was short-term (Fig. $3 d$ ). In particular, PPF in NAc decayed at $t_{\text {IPI }}>50 \mathrm{msec}$. Subsequently, PPD was apparent in NAc as at all other loci (e.g., putamen) at all pulse intervals until full recovery by $t_{\mathrm{IPI}}=30 \mathrm{sec}$ (Fig. $3 d$ ). In NAc, only the data for lateral regions are illustrated for the entire range of pulse intervals; in ventromedial NAc, $[\mathrm{DA}]_{\mathrm{o}}$ evoked by $P_{2}$ between $50 \mathrm{msec}$ and $5 \mathrm{sec}$ after $P_{1}$ are usually too small for accurate and meaningful quantification (data not shown). Recovery from depression can be described by an exponential curve fit (data not shown) in NAc (lateral; $\tau=3.8 \mathrm{sec}$ ) similar to those observed previously in the caudate nucleus/putamen of primates (Cragg et al., 2002) and rodents (Kennedy et al., 1992; Abeliovich et al., 2000).

\section{PPF versus PPD: independent of differential uptake}

$[D A]_{o}$ measured after a single pulse is a function of both the underlying release per pulse and uptake in the rodent and primate (Wightman and Zimmerman, 1990; Cragg et al., 2000). The expression level, density, and rate of DA uptake by the DAT differ between the two populations of DA projections to the primate striatum (Donnan et al., 1991; Blanchard et al., 1994; Hurd et al., 1994; Madras and Kaufman, 1994; Ciliax et al., 1995; Cragg et al., 2000, 2002). Furthermore, there is a nonlinear concentration dependence of uptake. Thus, it was investigated whether the apparent phenotypes of paired-pulse plasticity were an epiphenomenon of differential DA uptake after the release events, in contrast to an effect of presynaptic management of $p r o b_{\mathrm{R}}$. The release caused by a single versus a paired stimulus $\left(t_{\mathrm{IPI}}=10 \mathrm{msec}\right)$ was compared at ventromedial and dorsolateral poles, NAc (vm) and putamen $(\mathrm{dl})$, respectively, during inhibition of the DAT [GBR 12909 (500 nM)]. Uptake inhibition significantly enhanced peak $[\mathrm{DA}]_{\mathrm{o}}$ (to $230-300 \%$ ) and extracellular lifetime after either pulse protocol in both regions (Fig. $4 a, b)(n=5-6)$ but did not significantly modify paired-pulse ratios in either putamen (Fig. 4a) (control, $0.20 \pm 0.09$; GBR, $0.20 \pm 0.04$ ) or NAc (Fig. 4b) (control, $1.64 \pm 0.30 ;$ GBR, $1.32 \pm 0.18)$. Thus, neither PPF in NAc nor PPD in putamen could be attributed to an effect, subsequent to release, of uptake.

\section{PPD is not attributable to variable input activity by $D_{2}$-like DA receptors or $\mathrm{GABA}_{\mathrm{A}}$ receptors}

The fast PPD ( $<50 \mathrm{msec})$ apparent in dorsal striatum was explored further in the dorsolateral putamen, in which depression was most marked. First, we determined whether PPD was a consequence of an autoinhibition of release by activation of $\mathrm{D}_{2}$-like DA receptors and/or buffered diffusion of DA overflow by $\mathrm{D}_{2}$ receptor binding (presynaptic or postsynaptic). Inclusion of the $\mathrm{D}_{2}$-like receptor antagonist sulpiride $(1 \mu \mathrm{M})$ did not modify DA release caused by either a single or paired stimulus $\left(t_{\mathrm{IPI}}=10\right.$ 

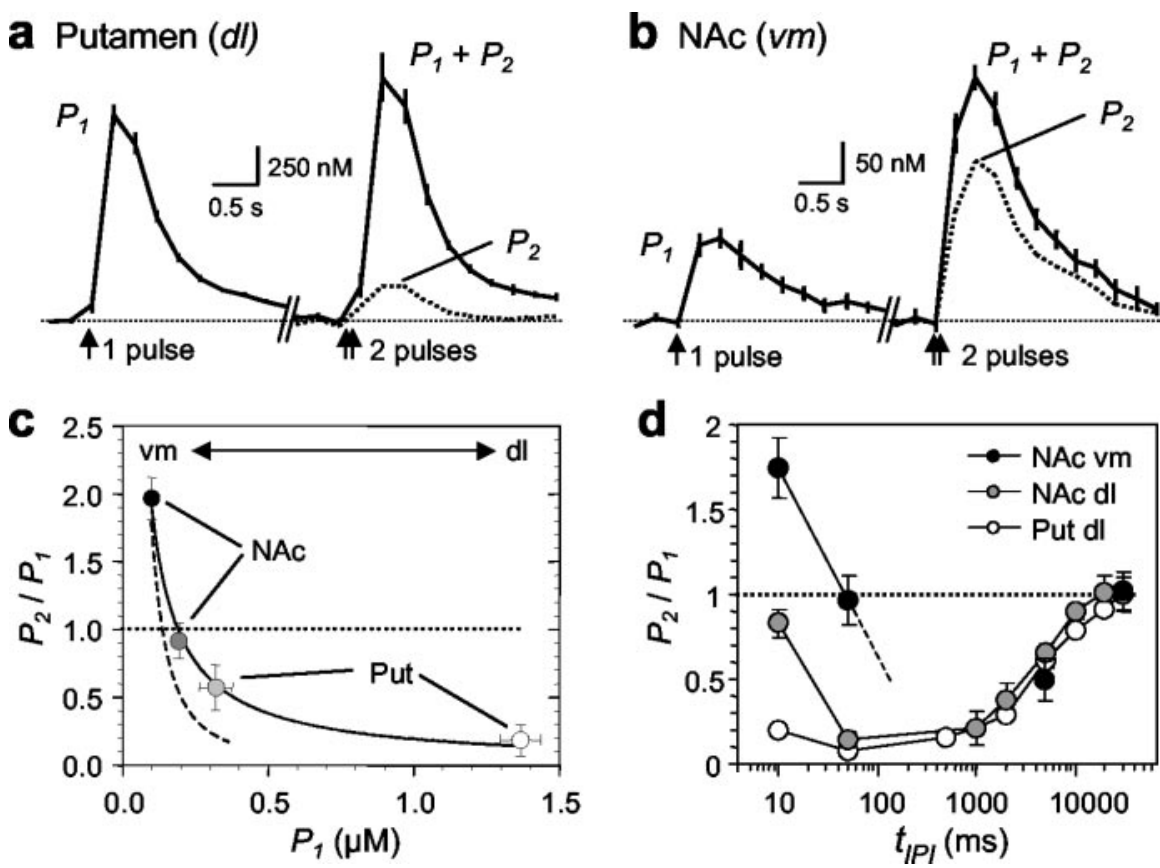

Figure 3. Short-term plasticity and striatal domain. $a, b$, Mean $[D A]_{0} \pm S E M$ (solid lines with hatching) versus time evoked (arrows) by a single pulse $\left(P_{1}\right)$ (left) or two pulses $\left(P_{1}+P_{2}\right)$ paired at $10 \mathrm{msec}(100 \mathrm{~Hz})$, administered when $P_{1}$ is reproducible (right) (see Materials and Methods). The release caused by the second pulse $\left(P_{2}\right)$ (dotted plot) is determined in all measurements by subtraction of $P_{1}$ from $P_{1}+P_{2}$. $a$, In putamen $(\mathrm{dl})$, a marked PPD is prominent $\left(P_{2}\right.$ vs $\left.P_{1} ; p<0.001 ; n=11-15\right)$. Calibration: $250 \mathrm{~nm}$ DA, $0.5 \mathrm{sec} . b$, In contrast, in NAc (vm), there is PPF ( $P_{2}$ vs $\left.P_{1} ; p<0.001 ; n=20-23\right)$. Calibration: $50 \mathrm{~nm}$ DA, 0.5 sec. $c$, The paired-pulse ratio $\left(P_{2} / P_{1}\right) \pm$ SEM at loci throughout the ventromedial-dorsolateral striatal extent is inversely related to $P_{1}(y=$ $a x^{-b} ; a=0.16 ; b=1.07 ; R^{2}>0.99 ;$ solid line; $n=7-23$ ). A similar relationship remains when $P_{2}$ is normalized for the regional, threefold variation in tissue DA content (Cragg et al., 2000) (dashed line; $R^{2}=0.97 ; a=0.03 ; b=1.8$ ). Dorsal striatum is associated with PPD, and ventral striatum is associated with PPF (parity; dotted line). Filled circles correspond to recording sites as indicated in Figure $2 a$. $d$, Paired-pulse plasticity \pm SEM varies dynamically with $t_{\mathrm{IP|}}(n=5-20)$. PPF in NAc decays at a $t_{\mid \mathrm{PI}}$ of $>50$ msec. PPD is immediate in dorsal striatum and residual in NAc (lateral) after $t_{\mathrm{IPI}}=50 \mathrm{msec}$; the paired-pulse ratio recovers to parity (dotted line) over time by an exponential relationship in NAc (data not shown) as in putamen (Put) (Cragg et al., 2002). Ventromedial NAc is not plotted between $t_{\mid \mathrm{PI}}$ of $50 \mathrm{msec}$ and $<5 \mathrm{sec}$, because a PPD (projected; dashed line) prevents accurate quantification of the low $[D A]_{0}$ in this region until $>5 \mathrm{sec}$.

msec; $n=3-6$ ) (Fig. 5a); in turn, rapid PPD was unaffected (Fig. $5 b, d) . \mathrm{D}_{2}$ receptors contributed to PPD only at $t_{\mathrm{IPI}} \mathrm{s}$ of $>50 \mathrm{msec}$ and $\leq 2 \mathrm{sec}$. The time of recovery to $100 \%$ of $P_{1}$ was not affected (Fig. $5 b$ ). These observations are consistent with the protracted time course of metabotropic autoreceptor inhibition of release by $\mathrm{D}_{2}$ receptors in mouse and rat striata reported previously (Benoit-Marand et al., 2001; Phillips et al., 2002). Thus, neither binding per se nor activation of DA metabotropic autoreceptors are components of the immediate PPD $(<50 \mathrm{msec})$ seen in dorsal striatum.

Second, we tested whether depression at $P_{2}$ was a result of activation of a more rapid (i.e., ionotropic) conductance (e.g., via the $\mathrm{GABA}_{\mathrm{A}}$ receptor caused by GABA released by $P_{1}$ ). Antagonism of $\mathrm{GABA}_{\mathrm{A}}$ receptors [bicuculline $(10 \mu \mathrm{M})$ ] did not modify single- or paired-pulse $\left(t_{\mathrm{IPI}}=10 \mathrm{msec}\right)$ release (Fig. $\left.5 c\right)(n=6-7)$ or, in turn, PPD (Fig. $5 d$ ). Thus, GABA $_{\mathrm{A}}$ receptor activation is not a component of PPD at this or any other $t_{\mathrm{IPI}}$ (data not shown). $\mathrm{GABA}_{\mathrm{B}}$ metabotropic receptor effects on fast PPD were not explored, because (1) their presynaptic action on GABA release in the rat hippocampus (Davies and Collingridge, 1993) shows a protracted time course similar to that for $\mathrm{D}_{2}$-like receptors on $\mathrm{DA}$ release in striatum, and (2) the $\mathrm{GABA}_{\mathrm{B}}$ antagonist saclofen does not modify evoked DA release in the rodent dorsal striatum (Avshalumov et al., 2003).
Plasticity of prob $_{\mathrm{R}}$ is dependent on $\mathrm{Ca}^{2+}$ availability

Typically (e.g., at glutamate synapses), the occurrence of PPF or PPD depends on whether initial $\mathrm{Ca}^{2+}$ transients reach thresholds appropriate to prime and release available transmitter (Stevens and Wang, 1995; Thomson, 1997): PPF results from a $\mathrm{Ca}^{2+}$-dependent increase in vesicle release probability at the second pulse caused by remaining bound or other residual $\mathrm{Ca}^{2+}$ (Zucker, 1999). In this study, the extracellular concentration of $\mathrm{Ca}^{2+}$ $\left(\left[\mathrm{Ca}^{2+}\right]_{0}\right)$ was manipulated to determine the $\mathrm{Ca}^{2+}$ limitations on the probability of DA release and, in turn, whether shortterm plasticity was a direct consequence of the initial probability of release. In other words, the activity dependence of shortterm plasticity was explored. In dorsolateral putamen, where PPD occurs, a halving of $\left[\mathrm{Ca}^{2+}\right]_{\mathrm{o}}$ from 2.4 to $1.2 \mathrm{~mm}$ significantly reduced both single- and paired-pulse $\left(t_{\mathrm{IPI}}\right.$ $=10 \mathrm{msec}$ ) release by twofold to threefold (Fig. 6a) $(n=4)$ and reduced PPD. The paired-pulse ratio was enhanced by approximately threefold from $0.17 \pm 0.03$ to $0.48 \pm 0.17(p<0.01)$, although it remained significantly depressed compared with $P_{1}(p<0.01)$. In ventromedial NAc, in which PPF is prominent, a doubling in $\left[\mathrm{Ca}^{2+}\right]_{\mathrm{o}}$ (to $4.8 \mathrm{~mm}$ ) enhanced $P_{1}$ by approximately twofold (Fig. $6 b)(p<0.01)$ yet reduced $P_{2}$ release by approximately threefold $\left(t_{\mathrm{IPI}}=10 \mathrm{msec} ; p<0.001\right.$ ) (Fig. $6 b)$. In fact, the paired release ratio was inverted by this increase in $\left[\mathrm{Ca}^{2+}\right]_{\mathrm{o}}$ from a $\operatorname{PPF}(1.64 \pm 0.26)$ to a level of PPD $(0.28 \pm$ $0.12, p<0.001)$ equivalent to that occurring in putamen at less than one-half of this $\left[\mathrm{Ca}^{2+}\right]_{\mathrm{o}}$.

\section{Discussion}

By observing neurotransmitter release directly using fast-scan cyclic voltammetry, presynaptic function can be assessed without the confounding effects of postsynaptic responses (Atwood and Karunanithi, 2002). We explored the dynamic plasticity in DA release and illustrate that the probability of axonal release of DA, like that of GABA, glutamate, and $\mathrm{ACh}$, exhibits a repertoire of release probabilities and short-term dynamics. Notably, DA release probability and short-term plasticity are specific to DA neuron types innervating, and, in turn, particular functional domains of, the primate striatum (Kunzle, 1975; Szabo, 1980; Selemon and Goldman-Rakic, 1985; Lynd-Balta and Haber, 1994b; Haber and McFarland, 1999).

A regional heterogeneity in the $\operatorname{prob}_{\mathrm{R}}$ of DA was apparent from the discrepancy between the release compared with the underlying packing density of DA: the 20 -fold greater [DA $]_{\mathrm{o}}$ evoked by a single pulse in dorsolateral (sensorimotor) compared with ventromedial (limbic-associated) striatum exceeded the regional variation in DA packing density [DA content (Cragg et al., 2000); DA transporter density (Madras and Kaufman, 1994)] by an order of magnitude. In fact, given that the monitored peak of $[\mathrm{DA}]_{\mathrm{o}}$ is modified slightly by local DA uptake and that the maximum rate of DA 
a Putamen

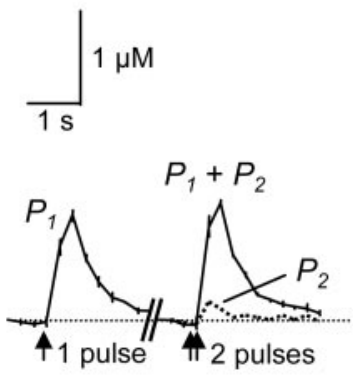

b NAC

$$
\prod_{1 \mathrm{~s}} 100 \mathrm{nM}
$$

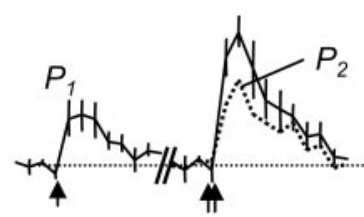

GBR 12909

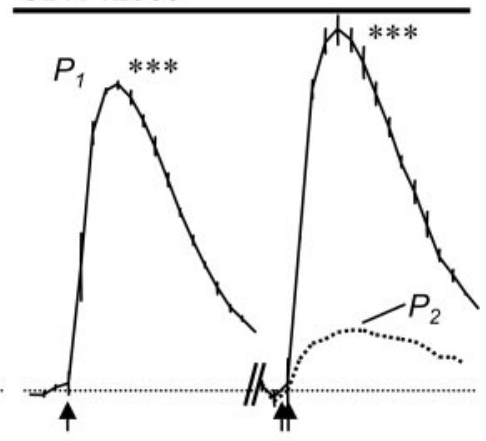

GBR 12909

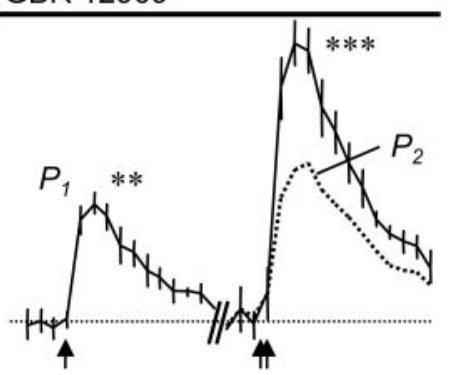

Figure 4. Variable short-term plasticity is not attributable to uptake. $a, b$, Mean $[\mathrm{DA}]_{0} \pm$ SEM (solid lines with hatching) versus time evoked (arrows) by $P_{1}, P_{1}+P_{2}\left(t_{\mid \mathrm{PI}}=10 \mathrm{msec}\right)$, and $P_{2}$ (dotted plot) in putamen (dorsolateral) $(a)$ and NAC (ventromedial) $(b)$ during control (left) and DAT inhibition [GBR 12909 (500 nM); solid bar] (right). $a$, In putamen, DAT inhibition enhances lifetime and peak $[D A]_{0}$ of $P_{1}$ and $P_{1}+P_{2}$ compared with control $\left({ }^{* *} p<0.001\right)$, but the PPD is not modified ( $n=5-6)$. Calibration: $1 \mu \mathrm{M} \mathrm{DA}, 1$ sec. $b$, In NAc, DAT inhibition enhances lifetime and peak $[\mathrm{DA}]_{0}$ of $P_{1}$ and $P_{1}+P_{2}$ compared with control $\left({ }^{* *} p<0.01\right.$; $\left.{ }^{* * *} p<0.001\right)$, but the PPF is not significantly modified $(n=5-6)$. Calibration: $100 \mu \mathrm{M} \mathrm{DA}$, $1 \mathrm{sec}$.

uptake is more than twofold greater in dorsal versus ventral striatum (Cragg et al., 2000), the underlying difference in prob $b_{\mathrm{R}}$ between regions may be greater yet (Fig. 4 , compare $a$ with $b$ ).

Paired-pulse studies corroborated the higher probability of DA release in motor than in limbic striatum and simultaneously revealed the range of short-term plasticity operating at different release sites; paired-pulse release ratio is a function of the ventromedial-dorsolateral coordinate. Because innervation territories of the two major populations of mesostriatal DA projections (Lynd-Balta and Haber, 1994a) follow a parallel ventromedialdorsolateral pattern, these differences in $\operatorname{prob}_{\mathrm{R}}$ are likely to be a function of DA neuron types. The release in response to a rapidly paired $\left(t_{\mathrm{IPI}}=10 \mathrm{msec}\right)$ pulse in dorsolateral putamen exhibited a large PPD $(>80 \%)$ consistent with a relatively high initial prob $b_{\mathrm{R}}$ from A9 (and therefore large release, $P_{1}$ ) (Fig. $3 c$ ). Conversely, in ventromedial NAc, a PPF of $\sim 100 \%$ was observed, in keeping

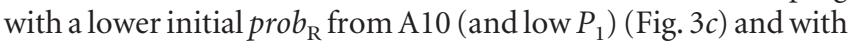
a subsequent elevation of probability at $P_{2}$ by temporal summation of some underlying component(s) to threshold (see below). At more central loci (with mixed A9 and A10 inputs), PPD or PPF were less apparent; for example, at loci in lateral NAc, an apparent parity of release $\left(P_{2} / P_{1}=1\right)$ was observed, as seen previously in rat NAc in vivo (Garris et al., 1994). The current study in primate striatum, however, reveals a wider repertoire of pairedpulse responses, ranging from PPD to PPF, which, moreover, are not necessarily a fixed feature of an entire striatal nucleus but rather can be a function of a more discrete subregion. The spec- trum of paired-pulse responses observed is consistent with each recording site comprising multiple release sites (Stamford et al., 1986) of a specific combination of mesostriatal inputs of mixed prob $_{\mathrm{R}}$ according to coordinate. At different striatal coordinates along the vm-dl axis, different release sites will be endowed with a continuously varying mixed input (Lynd-Balta and Haber, 1994a) by both high (A9; nigrostriatal) and low (A10; mesolimbic) prob $_{\mathrm{R}}$ neurons. The functional differentiation of striatal DA release sites revealed in this study correlates well not only with the innervation territories of the two mesostriatal dopaminergic populations (Lynd-Balta and Haber, 1994a) but also with the compartmentalization of the primate striatum into functional subterritories (Kunzle, 1975).

In studies of single synapses for GABA/glutamate, release failure rate can be used to indicate absolute $\operatorname{prob}_{\mathrm{R}}$. In the present study, however, release failure in response to a single pulse is seldom observed, because this would require that the summed release probabilities of the multiple possible sites for release be less than the fraction of total sites represented by each (e.g., $\Sigma$ prob $_{\mathrm{R}}<0.05$ for 20 sites; individual prob $_{\mathrm{R}}<0.0025$ ); the resultant condition of near-zero individual prob $_{\mathrm{R}}$ is rarely seen in the CNS (Thomson, 2000). The absence of release failure with this method, contrary to one study in ventral striatum (Garris et al., 1994), does not indicate that release probability from DA neurons is high, but rather, that it is not near zero.

PPF was short-lived ( $<100 \mathrm{msec})$, indicating that the underlying plasticity in prob $_{\mathrm{R}}$ requires a close temporal coincidence of stimuli. This time course is consistent with the summation of dynamic intracellular component(s) significantly above a threshold for release when $P_{2}$ occurs within $100 \mathrm{msec}$. Nonetheless, short-term plasticity would also be apparent if other extrinsic factors differentially modified release or extracellular behavior of DA at $P_{1}$ or $P_{2}$. A primary-candidate factor that might cause a nonlinear (i.e., facilitated) change in $[D A]_{o}$ is uptake. However, uptake inhibition did not modify PPF or PPD. Furthermore, short-term PPD of DA release $\left(t_{\mathrm{IPI}}=10 \mathrm{msec}\right)$ was not caused by a variable activity between pulses of DA autoreceptors (or the buffered overflow that receptor binding per se might offer) or from transsynaptic $\mathrm{GABA}_{\mathrm{A}}$ receptor effects.

In contrast, the time courses of rapid PPD and PPF are consistent with those reported previously at other synapses (e.g., PPF for glutamate) (Stevens and Wang, 1995; Thomson, 1997), which result from a straightforward $\mathrm{Ca}^{2+}$-dependent increase in vesicle prob $_{\mathrm{R}}$ involving bound (priming) or other residual $\mathrm{Ca}^{2+}$ remaining at a second pulse (Zucker, 1999), which is insufficient for transmitter release by a single pulse. Given the $\mathrm{Ca}^{2+}$ limitations on short-term plasticity in this study, the $\operatorname{prob}_{\mathrm{R}}$ of DA is most likely regulated by a similar $\mathrm{Ca}^{2+}$-dependent mechanism. The elevation of $\left[\mathrm{Ca}^{2+}\right]_{0}$ in NAc would enhance priming mechanisms during $P_{1}$ and thus reduce release by $P_{2}$. The opposite scenario would occur in putamen and after reduced $\left[\mathrm{Ca}^{2+}\right]_{0}$. These data therefore suggest that $\mathrm{Ca}^{2+}$ availability to priming/ releasing machinery is most limited and/or buffered in ventromedial regions of striatum. Indeed, this heterogeneity between striatal domains reflects a known heterogeneity in the likely $\mathrm{Ca}^{2+}$-buffering properties of the different DA projections, as indicated by expression of $\mathrm{Ca}^{2+}$-binding proteins (e.g., calbindinD28k) (Gerfen et al., 1987; Haber et al., 1995).

The mechanisms responsible for the PPD observed over a more protracted time scale (100 msec to $20 \mathrm{sec}$ ) could be multiple. Synaptic depression can result from depletion of readily releasable vesicles or from other reductions in the prob $_{\mathrm{R}}$ independent of vesicle availability (e.g., release-site refractoriness) 
a

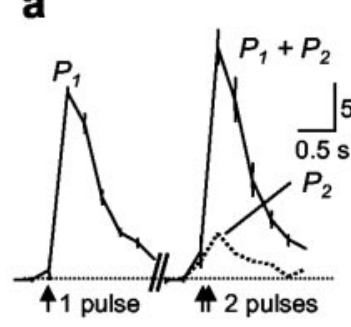

C

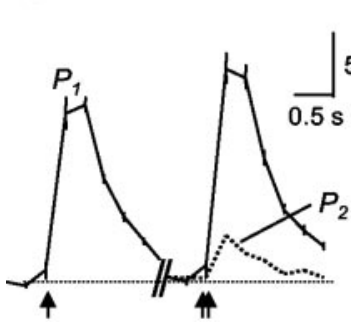

Sulpiride $(1 \mu \mathrm{M})$

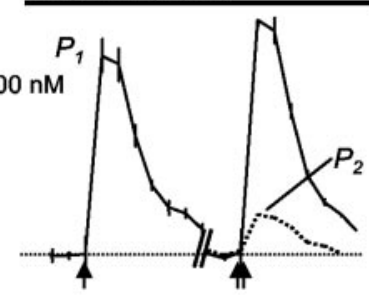

Bicuculline $(10 \mu \mathrm{M})$

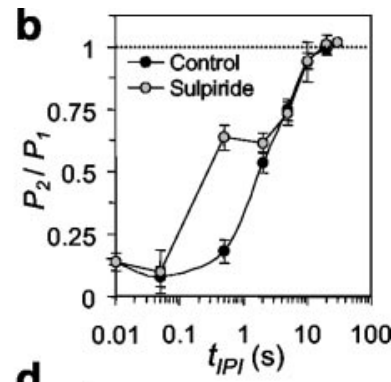

d

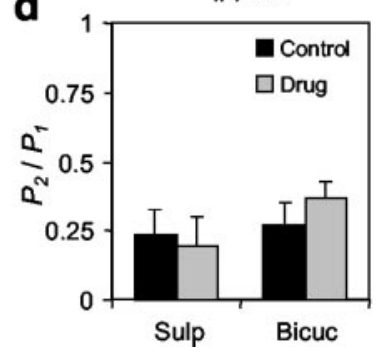

Figure 5. Eliminating variable input activity as a component of PPD. a, c, Mean $[D A]_{0} \pm S E M$ (solid lines with hatching) versus time in putamen (dorsolateral) evoked (arrows) by a single pulse $\left(P_{1}\right)$, paired pulses $\left(P_{1}+P_{2}\right)$, and a second pulse $\left(P_{2}\right.$; dotted plot) ( $\left.t_{\mid \mathrm{PI}}=10 \mathrm{msec}\right)$, during control (left) and antagonism of $\mathrm{D}_{2}$-like DA receptors [sulpiride $(1 \mu \mathrm{M})$ ] ( $a$ ) or $\mathrm{GABA}_{\mathrm{A}}$ receptors [bicuculline $(10 \mu \mathrm{M})$ ] (c) (solid bars) (right). Calibration: $500 \mathrm{~nm}$ DA, 0.5 sec. $a$, Sulpiride did not modify $P_{1}, P_{1}+P_{2}$, or $P_{2}$ compared with control at this $t_{\mid \mathrm{PI}}(n=3-6) . b$, Paired-pulse ratios $\pm S E M$ versus $t_{\mid \mathrm{PI}}$ in central (filled circles) and with sulpiride (gray circles) $t_{\mathrm{IPI}}$ is plotted logarithmically. The dynamic variation in PPD with $t_{\mathrm{IPI}}$ is modified by $\mathrm{D}_{2}$ receptors only at $>50 \mathrm{msec}$ and $<2 \sec \left({ }^{*} p<0.001\right)$. Dotted line indicates $P_{2}=P_{1}$. c B Bicuculline did not modify $P_{1}, P_{1}+P_{2}$, or $P_{2}$ compared with control $(n=$ $6-7) . d$, Paired-pulse ratios $\left(P_{2} / P_{1}\right) \pm$ SEM for each control (filled) versus drug treatment (shaded) in $a$ and c. Sulp, Sulpiride; Bicuc, bicuculline.

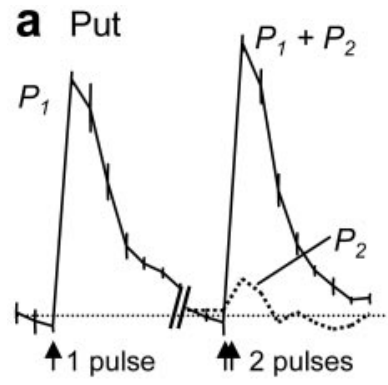

b NAC

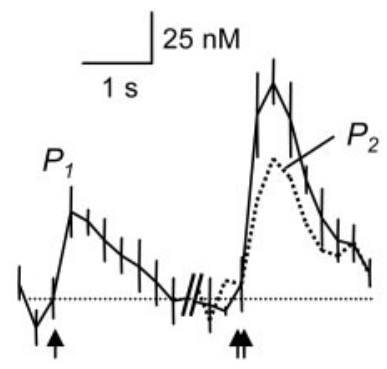

Reduced $\left[\mathrm{Ca}^{2+}\right]_{0}(1.2 \mathrm{mM})$
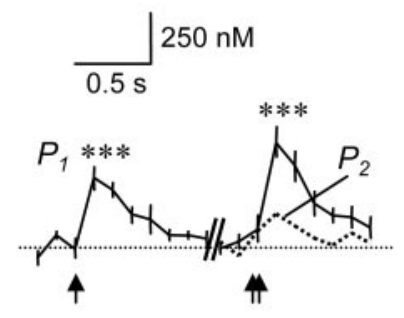

$\underline{\text { Increased }\left[\mathrm{Ca}^{2+}\right]_{0}(4.8 \mathrm{mM})}$

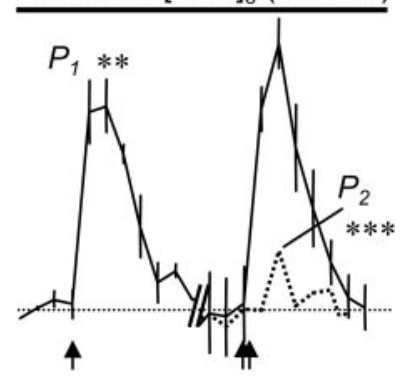

Figure 6. Modifying initial release probability alters short-term plasticity. Mean $[D A]_{0} \pm$ SEM (solid lines with hatching) versus time evoked (arrows) by a single pulse $\left(P_{1}\right)$, paired pulses $\left(P_{1}+P_{2}\right)$ and a second pulse $\left(P_{2} ;\right.$ dotted plot $)\left(t_{\mid \mathrm{PI}}=10 \mathrm{msec}\right)$ in putamen (Put; dorsolateral) (a) and NAC (ventromedial) (b) during control (left) and manipulation of $\left[\mathrm{Ca}^{2+}\right]_{0}$ (solid bar) (right). $a$, In putamen, halving $\left[\mathrm{Ca}^{2+}\right]_{0}$ to $1.2 \mathrm{~mm}$ reduces $P_{1}$ and $P_{1}+P_{2}$ compared with controls $(* * * p<0.001 ; n=4)$ but significantly enhances $P_{2} / P_{1}\left({ }^{* *} p<0.01\right)$. A significant PPD remains $\left(p<0.01 ; P_{2}\right.$ vs $\left.P_{1}\right)$. Calibration: $250 \mathrm{~nm} \mathrm{DA,} 0.5$ sec. $b$, In NAc, doubling $\left[\mathrm{Ca}^{2+}\right]_{0}$ to 4.8 mm enhances $P_{1}$ compared with control $\left({ }^{*} p<0.01 ; n=7\right)$ but not $P_{1}+P_{2} . P_{2}$ is markedly reduced ( $\left.{ }^{* * *} p<0.001\right)$, and PPF is significantly reduced (*** $\left.p<0.001\right)$ to a significant PPD $\left(p<0.001 ; P_{2}\right.$ vs $\left.P_{1}\right)$. Calibration: $25 \mathrm{~nm} \mathrm{DA}, 1 \mathrm{sec}$.

(Thomson, 2000). Intriguingly, the time course of recovery (Kennedy et al., 1992; Abeliovich et al., 2000; Cragg et al., 2002) is consistent with recovery of releasability after tetanic depletion at amino acid synapses (Stevens and Tsujimoto, 1995; Dobrunz and Stevens, 1997; Wang and Kaczmarek, 1998), which involves vesicle recapture, refill, and return to the releasable pool. However, on the basis of the assumptions that (1) DA release is univesicular per action potential (Matveev and Wang, 2000) per release site (univesicular release rule) and (2) as for glutamate, the releasable pool for DA contains more than one vesicle (Dobrunz and Stevens, 1997), the degree of depression of DA release after a single stimulus, attributable to depletion of the releasable pool, would be limited and therefore unlikely to contribute to this PPD. However, multivesicular release has been postulated within the CNS [e.g., at glutamate (Oertner et al., 2002) and GABA (Auger et al., 1998) synapses]. A hypothetical multivesicular release of DA would contribute to PPD by depletion.

Alternatively, PPD could arise readily via mechanisms independent of depletion and replenishment, by factor(s) that actively suppress $\operatorname{prob}_{\mathrm{R}}$. Metabotropic receptor activation and consequential modification of $\mathrm{Ca}^{2+}$ and/or $\mathrm{K}^{+}$conductances are such candidate mechanisms. However, the time scale of $\mathrm{D}_{2}$ auto- receptor effects is too latent to influence rapid PPD and too short to influence overall recovery time (Fig. 5b) (Benoit-Marand et al., 2001; Phillips and Stamford, 2002); $\mathrm{D}_{2}$ autoreceptor activation is only one of necessarily multiple factors responsible for PPD. One previous study suggests partial roles for $\mathrm{Ca}^{2+}$, firing mode, and $\alpha$-synuclein in slow PPD (Abeliovich et al., 2000). For other synapses, other independent changes in prob $_{\mathrm{R}}$ have been demonstrated to arise from changes in the probability that a given $\left[\mathrm{Ca}^{2+}\right]$ can permit exocytosis (Bellingham and Walmsley, 1999; $\mathrm{Wu}$ and Borst, 1999). For example, the apparent affinity of the release machinery to $\mathrm{Ca}^{2+}$ can be increased by protein kinase $\mathrm{C}$ acting at the release machinery downstream of the $\mathrm{Ca}^{2+}$ sensor (Wu and $\mathrm{Wu}, 2001$; Brager et al., 2002). Rab3-retarded fusion (Geppert et al., 1997; Thomson, 2000) is another possibility for release-site refractoriness, although the time courses observed here are more extended than those observed for this mechanism (Thomson, 2000).

In summary, we show that the probability of axonal DA release varies dramatically with functional domain and DA neuron type. An accompanying activity-dependent plasticity ranges from short-term depression to facilitation (or low- vs high-pass filters) in motor- to limbic-associated striatum, respectively. This variation in behavior is governed by $\mathrm{Ca}^{2+}$ availability. Thus, despite the extended temporal and spatial features of volume transmission by DA, rapid dynamics in DA release probability will nonetheless participate in the transmission of the pattern- and frequency-filter functions encoded by DA neuron action potential discharge. Furthermore, the variation in these features between DA neuron type will allow limbic- versus motor-associated 
DA neurons to transmit qualitatively different ranges of DA signals in response to the scope of DA neuron firing patterns.

\section{References}

Abeliovich A, Schmitz Y, Farinas I, Choi-Lundberg D, Ho WH, Castillo PE, Shinsky N, Verdugo JM, Armanini M, Ryan A, Hynes M, Phillips H, Sulzer D, Rosenthal A (2000) Mice lacking alpha-synuclein display functional deficits in the nigrostriatal dopamine system. Neuron 25:239-252.

Atwood HL, Karunanithi S (2002) Diversification of synaptic strength: presynaptic elements. Nat Rev Neurosci 3:497-516.

Auger C, Kondo S, Marty A (1998) Multivesicular release at single functional synaptic sites in cerebellar stellate and basket cells. J Neurosci 18:4532-4547.

Avshalumov MV, Chen BT, Marshall SP, Pena DM, Rice ME (2003) Glutamate-dependent inhibition of dopamine release in striatum is mediated by a new diffusible messenger, $\mathrm{H}_{2} \mathrm{O}_{2}$. J Neurosci 23:2744-2750.

Bellingham MC, Walmsley B (1999) A novel presynaptic inhibitory mechanism underlies paired pulse depression at a fast central synapse. Neuron 23:159-170.

Benoit-Marand M, Borrelli E, Gonon F (2001) Inhibition of dopamine release via presynaptic $\mathrm{D}_{2}$ receptors: time course and functional characteristics in vivo. J Neurosci 21:9134-9141.

Blanchard V, Raisman-Vozari R, Vyas S, Michel PP, Javoy-Agid F, Uhl G, Agid Y (1994) Differential expression of tyrosine hydroxylase and membrane dopamine transporter genes in subpopulations of dopaminergic neurons of the rat mesencephalon. Mol Brain Res 22:29-40.

Brager DH, Capogna M, Thompson SM (2002) Short-term synaptic plasticity, simulation of nerve terminal dynamics, and the effects of protein kinase $\mathrm{C}$ activation in rat hippocampus. J Physiol (Lond) 541:545-559.

Carboni E, Imperato A, Perezzani L, Di Chiara G (1989) Amphetamine, cocaine, phencyclidine and nomifensine increase extracellular dopamine concentrations preferentially in the nucleus accumbens of freely moving rats. Neuroscience 28:653-661.

Ciliax BJ, Heilman C, Demchyshyn LL, Pristupa ZB, Ince E, Hersch S, Niznik HB, Levey AI (1995) The dopamine transporter: immunocytochemical characterization and localization in brain. J Neurosci 15:1714-1723.

Cragg SJ, Greenfield SA (1997) Differential autoreceptor control of somatodendritic and axon terminal dopamine release in substantia nigra, ventral tegmental area, and striatum. J Neurosci 17:5738-5746.

Cragg SJ, Hille CJ, Greenfield SA (2000) Dopamine release and uptake dynamics within nonhuman primate striatum in vitro. J Neurosci 20:8209-8217.

Cragg SJ, Hille CJ, Greenfield SA (2002) Functional domains in dorsal striatum of the nonhuman primate are defined by the dynamic behavior of dopamine. J Neurosci 22:5705-5712.

Davies CH, Collingridge GL (1993) The physiological regulation of synaptic inhibition by $\mathrm{GABA}_{\mathrm{B}}$ autoreceptors in rat hippocampus. J Physiol (Lond) 472:245-265.

Descarries L, Watkins KC, Garcia S, Bosler O, Doucet G (1996) Dual character, asynaptic and synaptic, of the dopamine innervation in adult rat neostriatum: a quantitative autoradiographic and immunocytochemical analysis. J Comp Neurol 375:167-186.

Dobrunz LE, Stevens CF (1997) Heterogeneity of release probability, facilitation, and depletion at central synapses. Neuron 18:995-1008.

Donnan GA, Kaczmarczyk SJ, Paxinos G, Chilco PJ, Kalnins RM, Woodhouse DG, Mendelsohn FA (1991) Distribution of catecholamine uptake sites in human brain as determined by quantitative $\left[{ }^{3} \mathrm{H}\right]$ mazindol autoradiography. J Comp Neurol 304:419-434.

Fuxe K, Agnati LF (1991) Volume transmission in the brain. New York: Raven.

Garris PA, Ciolkowski EL, Pastore P, Wightman RM (1994) Efflux of dopamine from the synaptic cleft in the nucleus accumbens of the rat brain. J Neurosci 14:6084-6093.

Geppert M, Goda Y, Stevens CF, Sudhof TC (1997) The small GTP-binding protein Rab3A regulates a late step in synaptic vesicle fusion. Nature 387:810-814.

Gerfen CR, Baimbridge KG, Thibault J (1987) The neostriatal mosaic. III. Biochemical and developmental dissociation of patch-matrix mesostriatal systems. J Neurosci 7:3935-3944.

Gibb WRG, Lees AJ (1991) Anatomy, pigmentation, ventral and dorsal sub- populations of the substantia nigra, and differential cell death in Parkinson's disease. J Neurol Neurosurg Psychiatry 54:388-396.

Grace AA, Bunney BS (1984a) The control of firing pattern in nigral dopamine neurons: single spike firing. J Neurosci 4:2866-2876.

Grace AA, Bunney BS (1984b) The control of firing pattern in nigral dopamine neurons: burst firing. J Neurosci 4:2877-2890.

Haber SN, McFarland NR (1999) The concept of the ventral striatum in nonhuman primates. Ann NY Acad Sci 877:33-48.

Haber SN, Ryoo H, Cox C, Lu W (1995) Subsets of midbrain dopaminergic neurons in monkeys are distinguished by different levels of mRNA for the dopamine transporter: comparison with the mRNA for the $\mathrm{D}_{2}$ receptor, tyrosine hydroxylase and calbindin immunoreactivity. J Comp Neurol 362:400-410.

Haber SN, Fudge JL, McFarland NR (2000) Striatonigrostriatal pathways in primates form an ascending spiral from the shell to the dorsolateral striatum. J Neurosci 20:2369-2382.

Hurd YL, Pristupa ZB, Herman MM, Niznik HB, Kleinman JE (1994) The $\mathrm{DA}$ transporter and $\mathrm{DA} \mathrm{D}_{2}$ receptor mRNAs are differentially expressed in limbic- and motor-related subpopulations of human mesencephalic neurons. Neuroscience 63:357-362.

Hyland BI, Reynolds JNJ, Hay J, Perk CG, Miller R (2002) Firing modes of midbrain dopamine cells in the freely moving rat. Neuroscience 114:475-492.

Jones SR, Garris PA, Kilts CD, Wightman RM (1995) Comparison of dopamine uptake in the basolateral amygdaloid nucleus, caudate-putamen and nucleus accumbens of the rat. J Neurochem 64:2581-2589.

Kennedy RT, Jones SR, Wightman RM (1992) Dynamic observation of dopamine autoreceptor effects in rat striatal slices. J Neurochem 59:449-455.

Kish SJ, Shannak K, Hornykiewicz O (1988) Uneven pattern of dopamine loss in the striatum of patients with idiopathic Parkinson's disease: pathophysiologic and clinical implications. N Engl J Med 318:876-880.

Kunzle H (1975) Bilateral projections from precentral motor cortex to the putamen and other parts of the basal ganglia: an autoradiographic study in Macaca fascicularis. Brain Res 88:195-209.

Lynd-Balta E, Haber SN (1994a) The organization of midbrain projections to the striatum in the primate: sensorimotor-related striatum versus ventral striatum. Neuroscience 59:625-640.

Lynd-Balta E, Haber SN (1994b) Primate striatonigral projections: a comparison of the sensorimotor-related striatum and the ventral striatum. J Comp Neurol 345:562-578.

Madras BK, Kaufman MJ (1994) Cocaine accumulates in dopamine-rich regions of primate brain after i.v. administration: comparison with mazindol distribution. Synapse 18:261-275.

Matveev V, Wang XJ (2000) Implications of all-or-none synaptic transmission and short-term depression beyond vesicle depletion: a computational study. J Neurosci 20:1575-1588.

Oertner TG, Sabatini BL, Nimchinsky EA, Svoboda K (2002) Facilitation at single synapses probed with optical quantal analysis. Nat Neurosci 5:657-664.

Parent A, Mackey A, De Bellefeuille L (1983) The subcortical afferents to caudate nucleus and putamen in primate: a fluorescence retrograde double labeling study. Neuroscience 10:1137-1150.

Phillips PE, Hancock PJ, Stamford JA (2002) Time window of autoreceptormediated inhibition of limbic and striatal dopamine release. Synapse 44:15-22.

Rice ME (2000) Distinct regional differences in dopamine-mediated volume transmission. In: Volume transmission revisited (Agnati LF, Fuxe K, Nicholson C, Sykova E, eds), pp 275-288. Amsterdam: Elsevier Science.

Rusakov DA, Kullmann DM, Stewart MG (1999) Hippocampal synapses: do they talk to their neighbours? Trends Neurosci 22:382-388.

Schultz W (1986) Responses of midbrain dopamine neurons to behavioral trigger stimuli in the monkey. J Neurophysiol 56:1439-1461.

Selemon LD, Goldman-Rakic PS (1985) Longitudinal topography and interdigitation of corticostriatal projections in the rhesus monkey. J Neurosci 5:776-794.

Stamford JA, Kruk ZL, Millar J (1986) Sub-second DA release measured by in vivo voltammetry. Brain Res 381:351-355.

Stephan H, Baron G, Schwerdtfeger WK (1980) The brain of the common marmoset (Callithrix jacchus): a stereotaxic atlas. New York: Springer.

Stevens CF, Tsujimoto T (1995) Estimates for the pool size of releasable quanta at a single central synapse and for the time required to refill the pool. Proc Natl Acad Sci USA 92:846-849. 
Stevens CF, Wang Y (1995) Facilitation and depression at single central synapses. Neuron 14:795-802.

Szabo J (1980) Organization of the ascending striatal afferents in monkeys. J Comp Neurol 189:307-321.

Thomson AM (1997) Activity-dependent properties of synaptic transmission at two classes of connections made by rat neocortical pyramidal axons in vitro. J Physiol (Lond) 502:131-147.

Thomson AM (2000) Molecular frequency filters at central synapses. Prog Neurobiol 62:159-196.

Wang LY, Kaczmarek LK (1998) High-frequency firing helps replenish the readily releasable pool of synaptic vesicles. Nature 394:384-388.

Wightman RM, Zimmerman JB (1990) Control of dopamine extracellular concentration in rat striatum by impulse flow and uptake. Brain Res Brain Res Rev 15:135-144.

Wolfart J, Neuhoff H, Franz O, Roeper J (2001) Differential expression of the small-conductance, calcium-activated potassium channel SK3 is crit- ical for pacemaker control in dopaminergic midbrain neurons. J Neurosci 21:3443-3456.

Wu LG, Borst JG (1999) The reduced release probability of releasable vesicles during recovery from short-term synaptic depression. Neuron 23:821-832.

Wu XS, Wu LG (2001) Protein kinase C increases the apparent affinity of the release machinery to $\mathrm{Ca}^{2+}$ by enhancing the release machinery downstream of the $\mathrm{Ca}^{2+}$ sensor. J Neurosci 21:7928-7936.

Yung KKL, Bolam JP, Smith AD, Hersch SM, Ciliax BJ, Levey AI (1995) Immunocytochemical localization of $\mathrm{D}_{1}$ and $\mathrm{D}_{2}$ dopamine receptors in the basal ganglia of the rat: light and electron microscopy. Neuroscience 65:709-730.

Zucker RS (1989) Short-term synaptic plasticity. Annu Rev Neurosci $12: 13-31$.

Zucker RS (1999) Calcium- and activity-dependent synaptic plasticity. Curr Opin Neurobiol 9:305-313. 